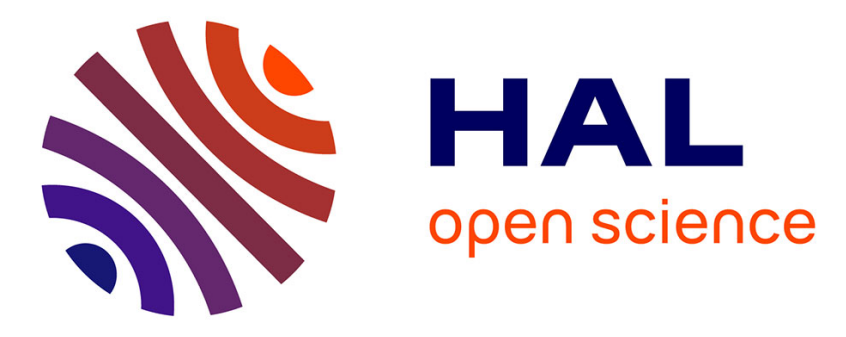

\title{
System level specification and multi-agent simulation of manufacturing systems
}

Khalil Aloui, Amir Guizani, Moncef Hammadi, Thierry Soriano, Mohamed Haddar

\section{- To cite this version:}

Khalil Aloui, Amir Guizani, Moncef Hammadi, Thierry Soriano, Mohamed Haddar. System level specification and multi-agent simulation of manufacturing systems. Advances in Materials, Mechanics and Manufacturing II, Springer International Publishing, pp.30-40, 2022, Lecture Notes in Mechanical Engineering, 10.1007/978-3-030-84958-0_4 . hal-03182941

\section{HAL Id: hal-03182941 https://hal.science/hal-03182941}

Submitted on 26 Mar 2021

HAL is a multi-disciplinary open access archive for the deposit and dissemination of scientific research documents, whether they are published or not. The documents may come from teaching and research institutions in France or abroad, or from public or private research centers.
L'archive ouverte pluridisciplinaire HAL, est destinée au dépôt et à la diffusion de documents scientifiques de niveau recherche, publiés ou non, émanant des établissements d'enseignement et de recherche français ou étrangers, des laboratoires publics ou privés. 


\title{
System level specification and multi-agent simulation of manufacturing systems
}

\author{
Khalil Aloui ${ }^{1,2}$, Amir Guizani ${ }^{2}$, Moncef Hammadi ${ }^{1}$, Thierry Soriano ${ }^{1}$, \\ Mohamed Haddar ${ }^{2}$ \\ ${ }^{1}$ QUARTZ Lab EA7393 - SUPMECA - 3 rue Fernand Hainaut 93400 Saint-Ouen, France \\ alouika95@gmail.com,moncef.hammadi@supmeca.fr, thierry.soriano@supmeca.fr \\ ${ }^{2}$ LA2MP, University of Sfax, Ecole National d'Ingénieurs, Sfax 3038, Tunisia \\ amir.guizani@live.fr, mohamed.haddar@enis.rnu.tn
}

\begin{abstract}
Lately, multi-agent systems (MAS) are being exploited to solve emerging challenges in manufacturing processes that require adaptation, flexibility, and reconfigurability. Multi-agent systems offer an alternative way to design and improve manufacturing processes and control systems due to their inherent abilities to adapt to emergence without external intervention. Multi-agent simulation assumes a crucial role to analyze and improve the manufacturing process during the design phase. Indeed, it is well suited to simulate manufacturing processes that present complex phenomena. This paper discusses the modeling and simulation of the steel converter process. The Systems Modeling Language (SysML) is used to illustrate the benefits of such tools in the manufacturing world on the specification of a steel converter process. A model of this process has been developed using SysML diagrams; and the simulation results are used to validate this model.
\end{abstract}

Keywords: Manufacturing systems, Multi-agent simulation, Systems Modeling Language (SysML), Simulation tool (Anylogic).

\section{Introduction}

Thanks to multi-agent systems (MAS), the design and manufacturing of control solutions have become more flexible, adaptive, and reconfigurable compared to traditional systems (Wooldridge, 2009). These systems are used to solve emerging challenges in the design and manufacture of industrial systems in terms of adaptation, flexibility and reconfigurability (Barbosa et al, 2011).

(Marik et al, 2005) have shown that MAS are characterized by the decentralization of the control of its distributed structures which provide robustness, modularity, and autonomy of the processes and solve at least $25 \%$ of manufacturing problems. For example, (Guizani et al, 2014a) have developed a new approach based on multi-agent technologies for the optimal design of mechatronic systems. 
The proposed approach is further improved by the development of a coordination and negotiation process allowing agents to facilitate the collaborative design of distributed systems (Guizani et al, 2014b). They subsequently validated this work through a test case to optimize the preliminary design of an electric vehicle (Guizani et al, 2017).

The multi-agent swarm framework can adequately represent characteristics of supply chains, such as multiple levels of abstraction and separation of concerns. Through this multi-agent model, individual agents are integrated with trust mechanisms to identify trusted partners to fulfill customer orders (Lin et al, 2005). In addition, the study of swarm robotic systems has been considered as a study of multi-agent systems. Developers of swarm robot systems use realistic simulators to test and accelerate the development of new design methods (Aloui et al, 2020). They use simulators to model the interactions between robots and the interactions of robots with their environment (Sahin et al, 2008). The software required to develop agents is simpler and shorter than the software required by centralized approaches (O'Hare et al, 1996). However, analyzing, testing, and validating the behavior of multi-agent systems is generally difficult and time-consuming. It is necessary to use tools that support the correction of errors during the design phase before its deployment in the real operation; These are the tools of multi-agent simulation that simplify the representation, the testing, and therefore the understanding of the behavior of the system.

In manufacturing, developers reduce the time and cost of developing control systems by using simulation which allows for the detection of errors, mistakes, and misunderstandings during the design phase and before moving on to implementation (De Vin et al, 2001). In this article, we study the steel converter process with the aim of developing a model that focuses on the crane management algorithm to minimize discontinuities in the operation of continuous casting machines. In the first part, we model this process using Systems Modeling Language (Mhenni et al, 2014). In fact, several SysML diagrams are used such as requirements diagram to specify system requirements, sequence diagram and state machine diagram to model system behavior, and block definition diagrams to identify structural architecture. In the second part, we use a multi-agent tool called "Anylogic" to simulate the modeled version and check the performances through the results obtained.

\section{Steel converter process}

Today, we use steel to fabricate everything from sewing needles to oil tankers. It is the most used material for building industries and the world's infrastructure (Tossavainen et al, 2007). In addition, all the tools required to build and manufacture are made of steel. The process of converting steel is very complicated (Kovalev et al, 2016). It can be simplified as follows: at first, the hot metal was 
treated in a converter where all secondary metallurgical work is done. Secondly, the hot metal is poured into a large refractory-lined container called a ladle and transported to the cranes. Then the filled ladles loaded through cranes and carried to the continuous casting machines (CCM). These machines are used to pour hot metal into molds. (Nutting et al, 2019).

In this paper, to develop a model of the steel converter process, the work mainly focused on the crane management algorithm to minimize discontinuities in the operation of continuous casting machines (CCM).

\subsection{System requirements}

To minimize discontinuities in the operation of continuous casting machines (CCMs), there are several constraints that cause difficulties. The requirements diagram shown in Figure 1 presents the main system requirements.

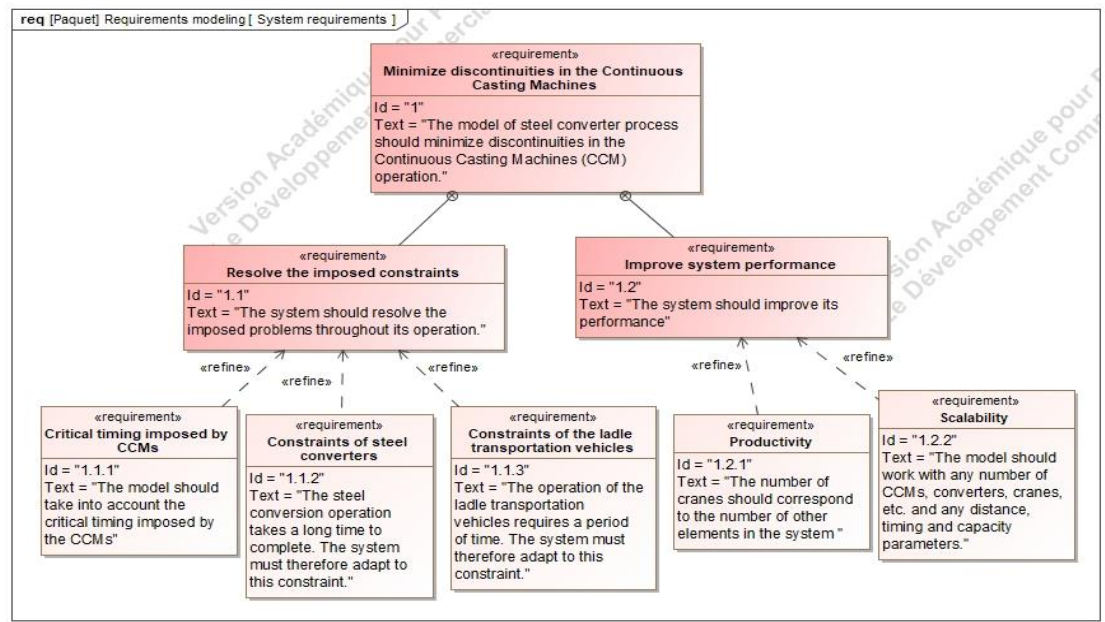

Fig. 1 System requirements

The critical timing is imposed by the CCMs and additional constrains come from the steel converters and the ladle transportation vehicles. For a good productivity, the number of cranes should correspond to the number of other elements in the system. In addition, the model should be highly scalable: it can work with any number of converters, cranes, CCMs, etc. and any timing, distance and capacity parameters.

\subsection{Behavior modeling}

Modeling behavior requires the identification of the main components of the system. As mentioned, the steel conversion process consists of converters where 
all secondary metallurgical work is done, ladles to transfer hot metal, cranes and continuous casting machines (CCM). Figure 2 represents the sequence diagram which describes the chronological order of the functional scenario of the system.

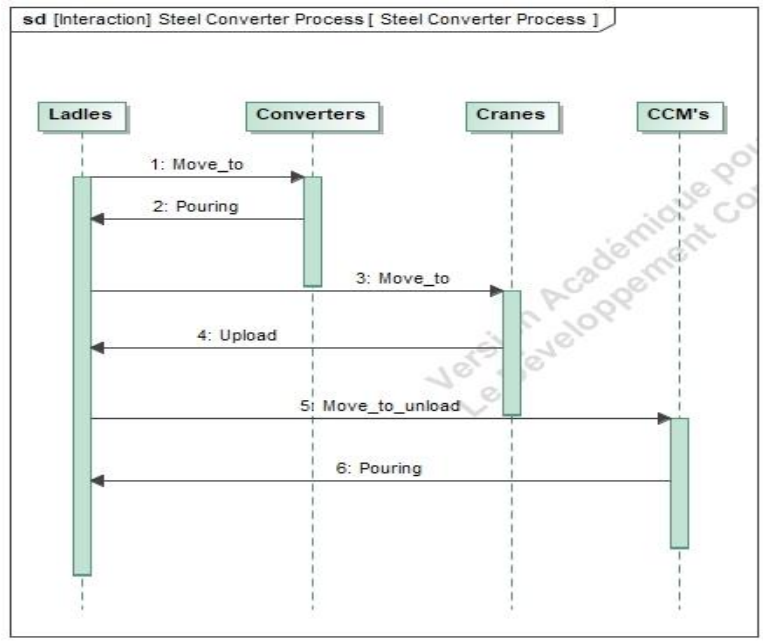

Fig. 2 Sequence diagram

At the beginning of the process, the empty ladles move to the converters for filling. The converters pour the hot metal into the ladles. The filled ladles are then moved to the cranes for loading onto the continuous casting machine (CCM). If the ladles connect to the continuous casting machines (CCM), these machines pour the hot metal into the molds and the process is repeated each time.

Figure 3 shows the state machine diagram of the hot metal transport activity throughout the process. The ladle waits to be full at the converter. If the filling is carried out, the ladle moves to the crane for loading. Then the empty ladle returns to the converter for refilling.

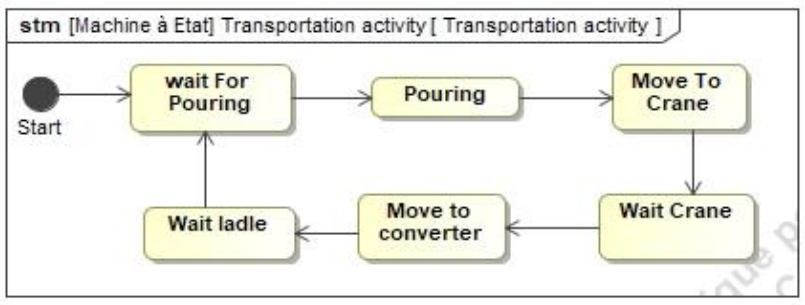

Fig. 3 State machine diagram of transportation activity

The state machine diagram shown in Figure 4 describes the crane activity. The crane awaits the arrival of the ladle; it moves towards target 1 where it checks 
whether there is a ladle or not. If there is a ladle, the crane loads it and moves towards target 2 to unload, otherwise, it returns to the wait step.

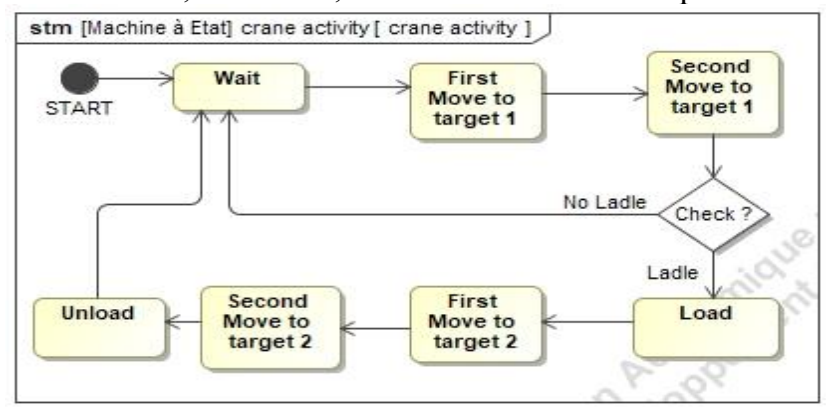

Fig. 4 State machine diagram of crane activity

The continuous casting of liquid steel into the mold is a very important step in the steel conversion process. This step is performed by a continuous casting machine (CCM). This machine is constituted by two right and left ladle holders. Its operating algorithm is illustrated in Figure 5. At first, the machine waits for the arrival of a ladle. The crane checks whether one of the two CCM ladle holders is filled or not. If the right ladle holder is empty, the crane loads the ladle into this ladle holder; otherwise, the CCM rotates $180^{\circ}$ so that the crane loads the ladle into the left ladle holder.

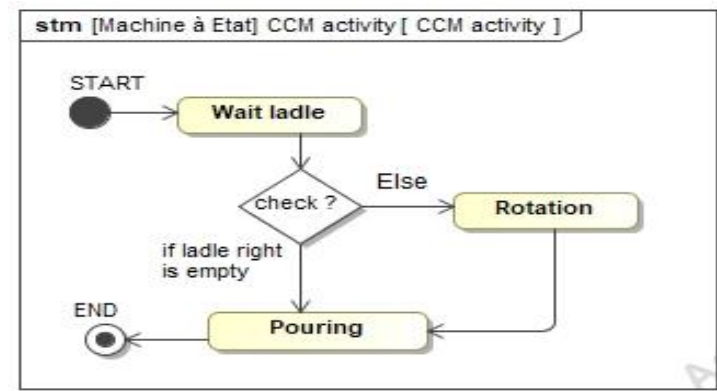

Fig. 5 State machine diagram of CCM activity

The simulation of the steel converter process requires the identification of the structural architecture of the system. That's why the next section discusses structural modeling of the system using block definition diagrams.

\subsection{Structural modeling}

In this section, the structural architecture of the process has been studied. Figure 6 represents the activity diagram which describes the general structure of the steel converter process. This process generally consists of four subsystems; 
two subsystems for pouring activity at converter and CCM level, and two subsystems for loading activity at converter and crane level.

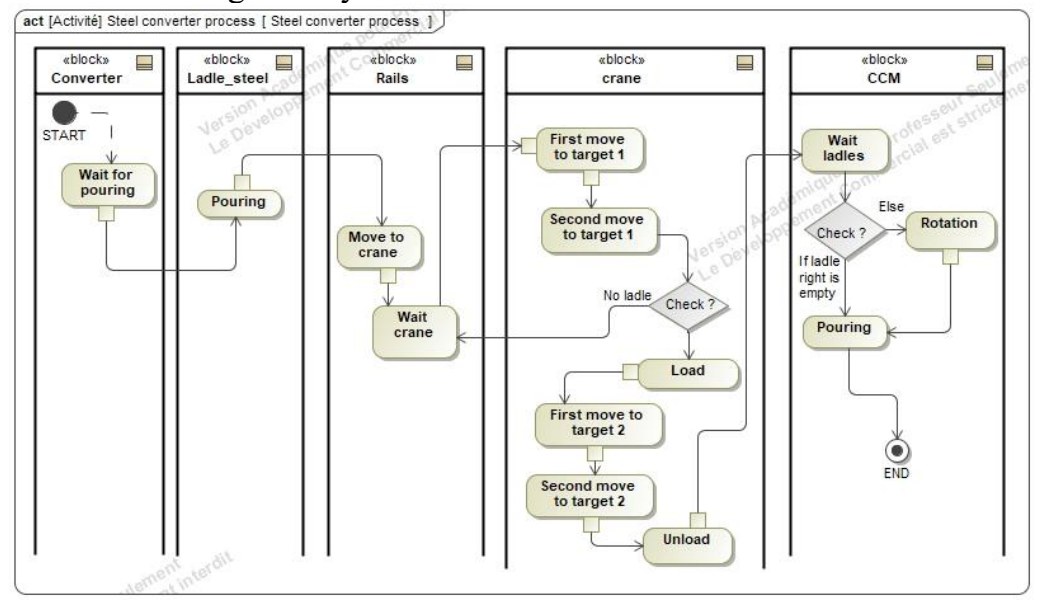

Fig. 6 The steel converter process

The block definition diagram shown in Figure 7 describes the components of the pouring system at the converter level. This subsystem consists of three converters, ten steel ladles and five rails. In fact, each component is characterized by a set of values that ensure the functioning of the system.

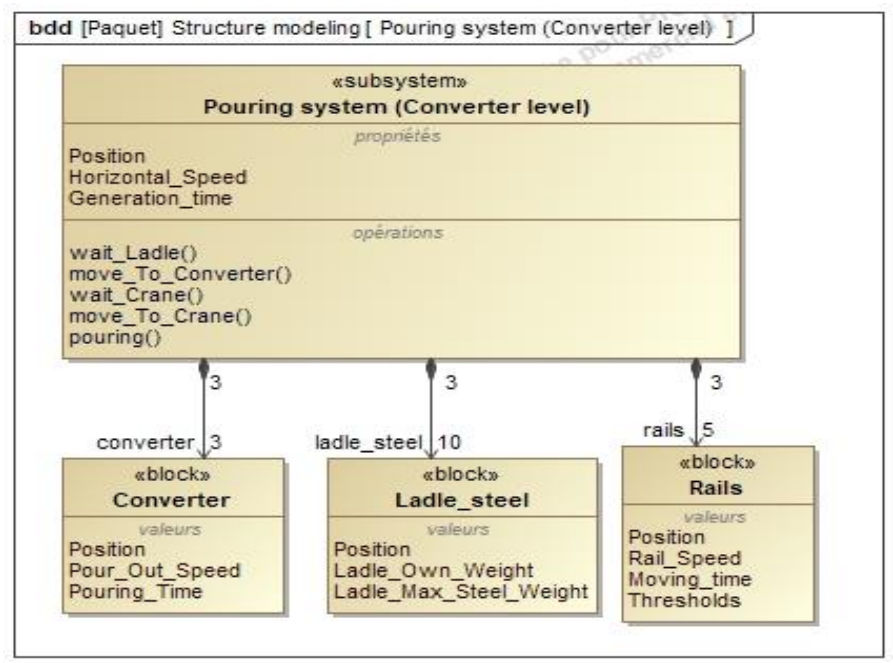

Fig. 7 Pouring system (Converter level) 
Likewise, the block definition diagram illustrated in Figure 8 describes the pouring system at the CCM level. This subsystem is made up of three CCM's and two ladles.

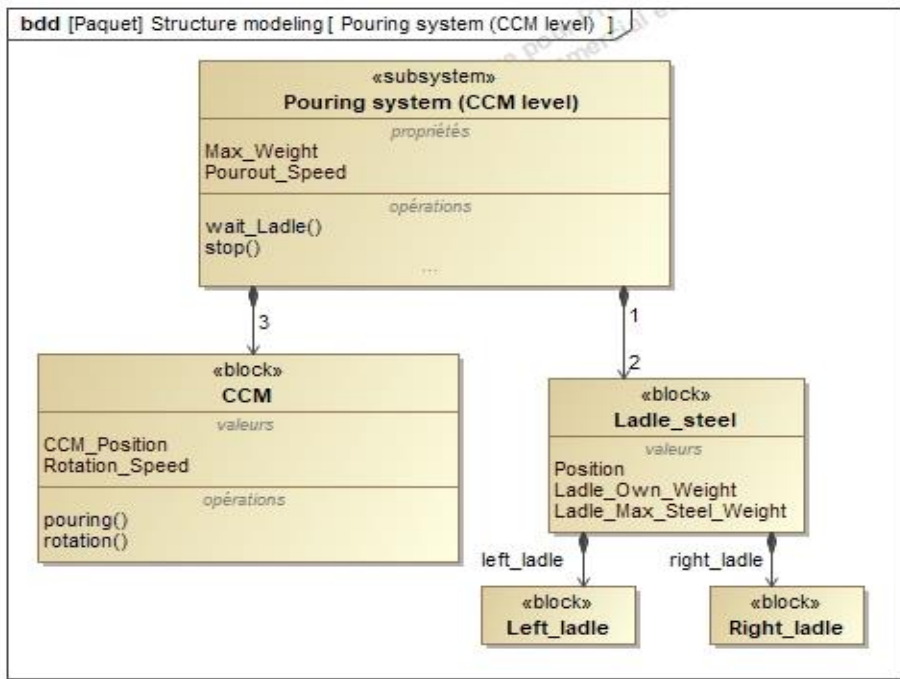

Fig. 8 Pouring system (CCM level)

The loading system at the converter level is shown in Figure 9. This subsystem consists of two ladles and five rails.

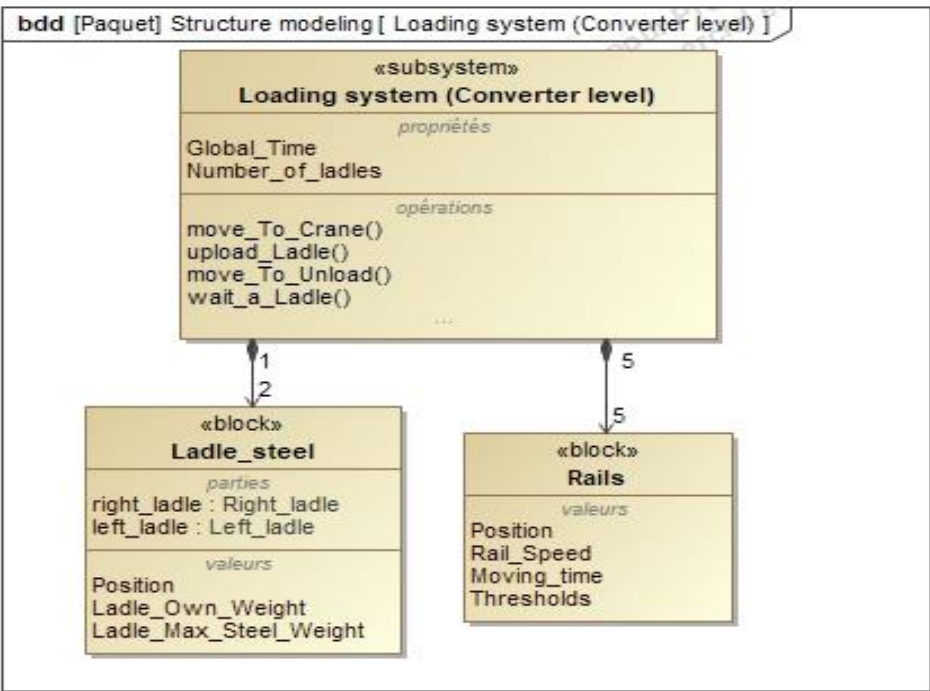

Fig. 9 Loading system (Converter level) 
Finally, the block definition diagram illustrated in Figure 10 defines the loading system at the crane level. This subsystem consists of rails, cranes, and ladles.

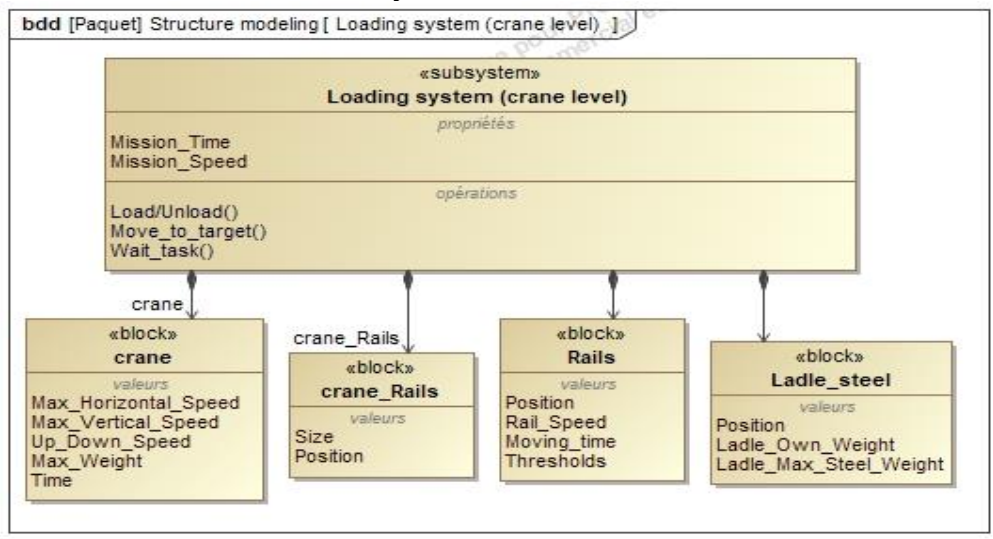

Fig. 10 Loading system (Crane level)

To ensure the continuity and consistency of the modeling approach, we use the allocation matrix and the traceability diagram. In fact, the allocation matrix illustrated in Figure 12 links the functions with its system components; and the traceability diagram illustrated in Figure 11 represents the links and the interactions between the different levels of the system.

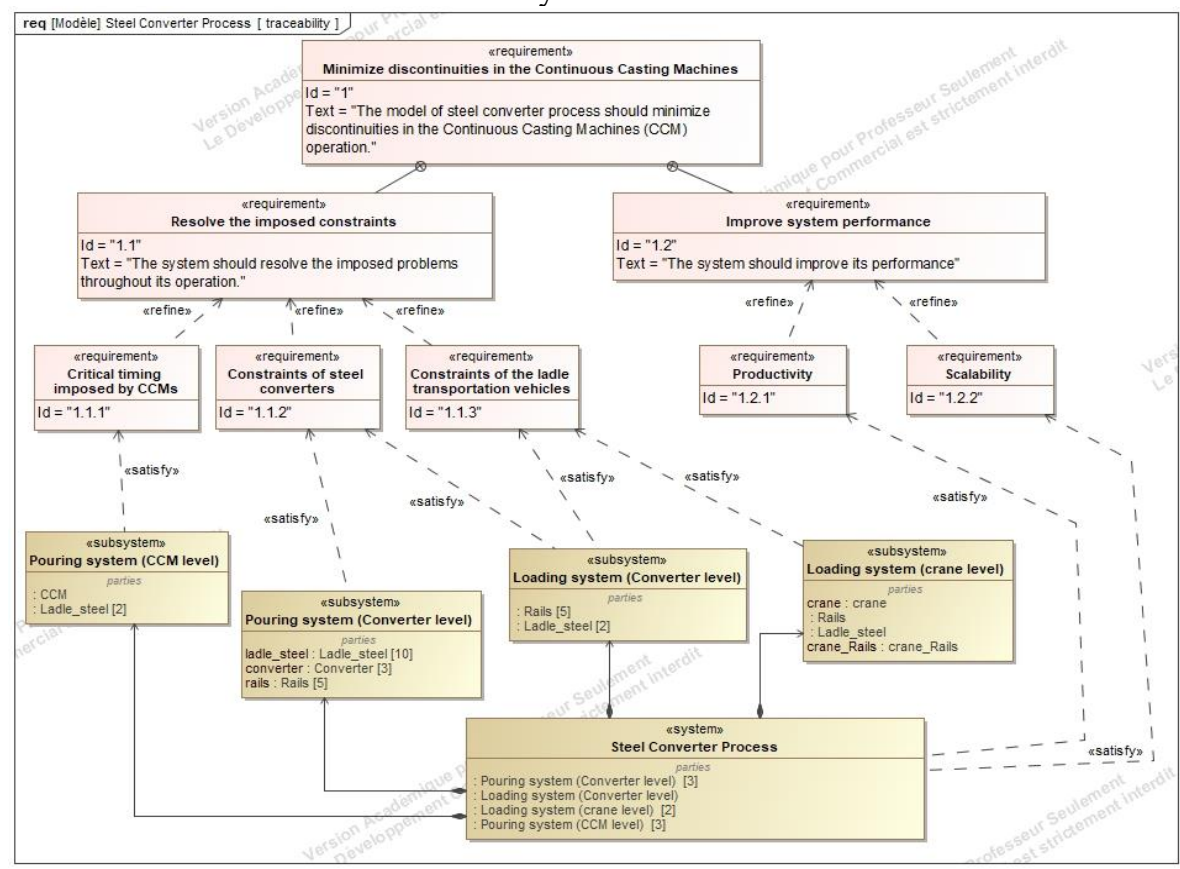

Fig. 11 Traceability diagram 


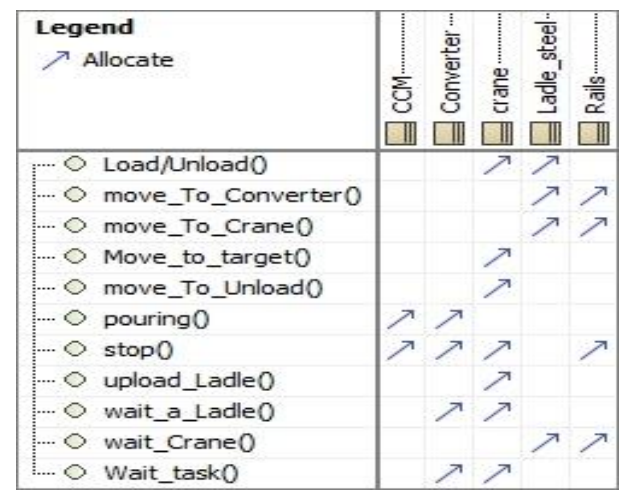

Fig. 12 Allocation matrix

\subsection{Multi-agent simulation}

In this section, we use a multi-agent simulation tool called "AnyLogic". This simulation tool has a graphical modeling language and also makes it easy to extend the simulation model with Java code (Borshchev et al, 2002).

Generally, the model of steel converter process focuses on crane management algorithm that should minimize discontinuities in the continuous casting machines (CCM) operation. Figure 13 represents the simulated model of the steel converter process.

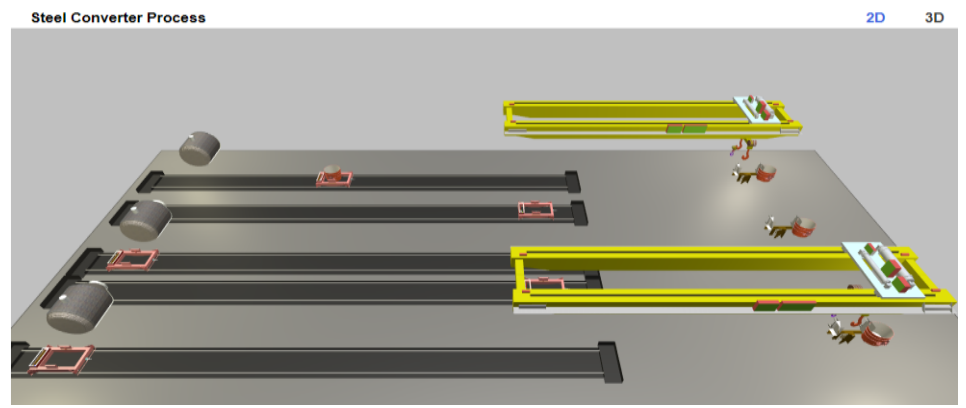

Fig. 13 Simulated model of the steel converter process

With the model developed in the previous sections, defining the simulation becomes easier. You just need to create the necessary components through the library found in the software (cranes, converters, CCM's, and ladles).

The aim of this work is to minimize discontinuities in the operation of continuous casting machines (CCM) to avoid solidification of the metal. Figure 14 represents the simulation results before and after the modification of the crane management algorithm. 


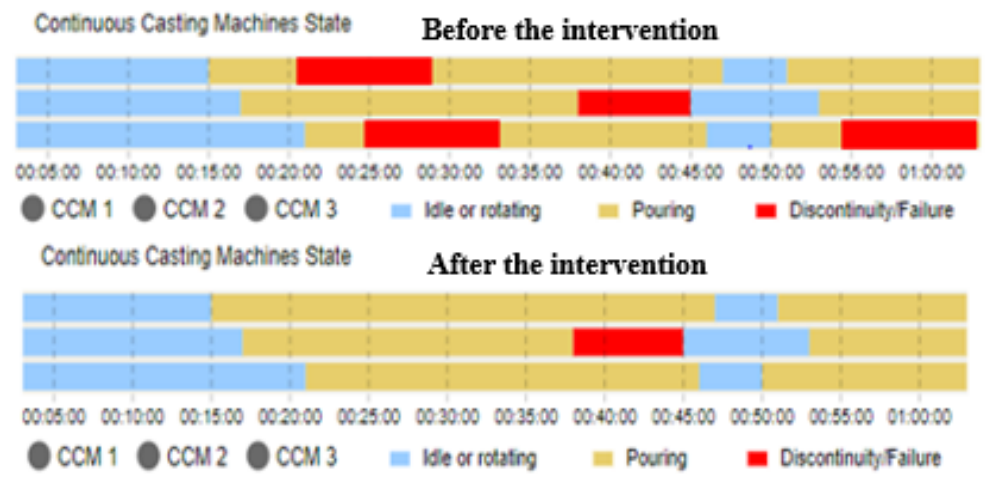

Fig. 14 Simulation results

Before the intervention, the crane management algorithm is insufficient; which causes discontinuities in the operation of continuous casting machines and solidification of the metal. That's why the model focuses on the crane management algorithm and modify it to minimize these discontinuities. Finally, the discontinuities in the operation of continuous casting machines are minimized.

\section{Conclusion}

In the field of manufacturing, the use of multi-agent systems facilitates the design of processes and the improvement of their performances. In fact, a multiagent simulation is a tool for analyzing, understanding, and optimizing manufacturing processes such as the steel converter process.

This paper discusses the use of SysML languages in modeling and the multi-agent tool in the simulation of agent-based manufacturing systems. Aiming to illustrate the applicability and benefits of using these tools in the modeling and simulation of agent-based systems, a steel converter process study was considered. For this purpose, the Anylogic tool was used as a simulation platform to focus on the crane management algorithm which should minimize discontinuities in the operation of continuous casting machines (CCM).

As a future work, the developed model will continue to be used to finalize the specification of the steel converter process. Also, and due to some Anylogic limitations, the logical step is to move into a more powerful software. 


\section{References}

Aloui, K., Hammadi, M., Soriano, T., Guizani, A., \& Haddar, M. (2020). On the continuity of the swarm robot design using MBSE method and simulation. 13th International Conference on Modelling, Optimization and Simulation (MOSIM'20),

Barbosa, J., \& Leitão, P. (2011). Simulation of multi-agent manufacturing systems using agent-based modelling platforms. 2011 9th IEEE International Conference on Industrial Informatics, (pp. 477-482).

Borshchev, A., Karpov, Y., \& Kharitonov, V. (2002). Distributed simulation of hybrid systems with AnyLogic and HLA. Future Generation Computer Systems, 18, 829-839.

De Vin, L. J., \& Jagstam, M. (2001). Why we need to offer a modeling and simulation engineering curriculum. Proceeding of the 2001 Winter Simulation Conference (Cat. No. 01CH37304), 2, pp. 1599-1604.

Guizani, A., Hammadi, M., Choley, J.-Y., Soriano, T., Abbes, M. S., \& Haddar, M. (2014a). Agent-Based Approach for the Optimal Design of Mechatronic Systems. Conference on Multiphysics Modelling and Simulation for Systems Design, pp. 189-198)

Guizani, A., Hammadi, M., Choley, J.-Y., Soriano, T., Abbes, M. S., \& Haddar, M. (2014b). Agent-based approach for collaborative distributed mechatronic design. 2014 10th France-Japan/8th Europe-Asia Congress on Mecatronics (MECATRONICS2014-Tokyo), pp. 156-161.

Guizani, A., Hammadi, M., Choley, J.-Y., Soriano, T., Abbes, M. S., \& Haddar, M. (2017). Multi-agent approach based on a design process for the optimization of mechatronic systems. Mechanics \& Industry, 18, 507.

Ives, D., Miller, L., Gara, V., Lanigan, J., Nutting, J., Onus, F., . . . others. (2019). Everyday Brave: Media Nomads: Thaiday Brothers-Ep 5 Of 6.

Kovalev, P. V., Ryaboshuk, S. V., Issagulov, A. Z., Kulikov, V. Y., Kvon, S. S., Chsherbakova, Y. P., . . . Jironkin, M. V. (2016). Improving production technology of tube steel grades in converter process. Metalurgija, 55, 715-718.

Lin, F.-r., Sung, Y.-w., \& Lo, Y.-p. (2005). Effects of trust mechanisms on supply-chain performance: A multi-agent simulation study. International Journal of Electronic Commerce, 9, 9-112.

Luke, S., Cioffi-Revilla, C., Panait, L., Sullivan, K., \& Balan, G. (2005). Mason: A multiagent simulation environment. Simulation, 81, 517-527.

Marik, V., \& McFarlane, D. (2005). Industrial adoption of agent-based technologies. IEEE Intelligent Systems, 20, 27-35.

Mhenni, F., Choley, J.-Y., Penas, O., Plateaux, R., \& Hammadi, M. (2014). A SysMLbased methodology for mechatronic systems architectural design. Advanced Engineering Informatics, 28, 218-231.

O'Hare, G. M., \& Jennings, N. R. (1996). Foundations of distributed artificial intelligence (Vol. 9). John Wiley \& Sons. 
Şahin, E., Girgin, S., Bayindir, L., \& Turgut, A. E. (2008). Swarm robotics. Dans Swarm intelligence (pp. 87-100). Springer.

Tossavainen, M., Engstrom, F., Yang, Q., Menad, N., Larsson, M. L., \& Bjorkman, B. (2007). Characteristics of steel slag under different cooling conditions. Waste management, 27, 1335-1344.

Vrba, P., \& Marcík, V. (2005). Simulation in agent-based control systems: MAST case study. IFAC Proceedings Volumes, 38(1), 145-152.

Wooldridge, M. (2009). An introduction to multiagent systems. John wiley \& sons. 